2 Hutchison DC, Flenley DC, Donald KW. Controlled oxygen therapy in respiratory failure. BMJ 1964; 2: 1159-1166.

3 Austin MA, Wills KE, Blizzard L, et al. Effect of high flow oxygen on mortality in chronic obstructive pulmonary disease patients in prehospital setting: randomised controlled trial. BMJ 2010; 341: c5462.

4 O'Driscoll BR, Beasley R. Avoidance of high concentration oxygen in chronic obstructive pulmonary disease. BMJ 2010; 341: c5549.

5 Rønning OM, Guldvog B. Should stroke victims routinely receive supplemental oxygen? A quasi-randomized controlled trial. Stroke 1999; 30: 2033-2037.

6 Kilgannon JH, Jones AE, Shapiro NI, et al. Association between arterial hyperoxia following resuscitation from cardiac arrest and in-hospital mortality. JAMA 2010; 303: 2165-2171.

7 de Jonge E, Peelen L, Keijzers PJ, et al. Association between administered oxygen, arterial partial oxygen pressure and mortality in mechanically ventilated intensive care unit patients. Crit Care 2008; 12: R156.

8 O'Driscoll BR, Howard LS, Davison AG. British Thoracic Society Guideline for emergency oxygen use in adult patients. Thorax 2008; 63: Suppl. 6, 1-68.

9 Hale KE, Gavin C, O'Driscoll BR. An audit of oxygen use in emergency ambulances and in a hospital emergency department. Emerg Med J 2008; 25: 733-736.

10 O'Leary MJ. Re: Oxygen therapy in COPD. www.bmj.com/ content/341/bmj.c5549/reply. Date last updated: November 9, 2010. Date last accessed: October, 26: 2011.

\title{
Cat litter is a possible trigger for sarcoidosis
}

\section{To the Editors:}

Sarcoidosis is characterised by cellular immune activity with noncaseating granuloma formation in various organ systems with a multifactorial cause. Many causative agents are considered to be involved in the pathogenesis [1-5]. Geneenvironment interactions offer the potential for strengthening the evidence of causation between exposures and sarcoidosis. It is important to identify every potential exposure to triggers in order to avoid irreversible damage. Inorganic agents, including silica, have been reported to initiate inflammation and granulomatous reactions $[6,7]$. It is well known that cats can cause allergic reactions, but less is known about the association of inflammation and cat litter. We propose that silica, the major component of cat litter, might be such an agent. We report a case of biopsy-proven sarcoidosis with birefringent material, mainly silica, within the lung biopsy specimen. The patient had no relevant occupational history, but had cats and was extensively exposed to silica-containing cat litter. Initially, the patient improved after starting immunosuppressive drugs and terminating contact with litter. However, she deteriorated twice after autoprovocation (re-exposure) to cat litter. After changing the silica-containing cat litter for litter without silica, her clinical condition improved substantially. Obviously, she appeared to be "hypersensitive" not to the cats but to the cat litter.

A 44-yr-old female was admitted to the former ILD Care Team (a tertiary referral centre) of the Dept of Respiratory Medicine, Maastricht University Medical Centre (Maastricht, the Netherlands). The patient had been diagnosed with sarcoidosis 4 yrs prior to admission. She had no medical history and did not smoke or use any medication. The diffusing capacity of the lung for carbon monoxide was impaired (62\% predicted). A chest radiograph demonstrated a micronodular interstitial pattern without enlargement of lymph nodes (stage III), and was confirmed by a high-resolution computed tomography (CT) scan. Inflammatory signs of sarcoidosis were increased, including angiotensin-converting enzyme (ACE) (30 U. $\mathrm{L}^{-1}$, normal range $9-25 \mathrm{U} \cdot \mathrm{L}^{-1}$ ) and soluble interleukin-2 receptor (sIL-2R) $\left(4,518 \mathrm{pg} \cdot \mathrm{mL}^{-1}\right.$, reference range $\left.240-3,154 \mathrm{pg} \cdot \mathrm{mL}^{-1}\right)$, and a wholebody ${ }^{18} \mathrm{~F}$-2-fluoro-2-deoxy-D-glucose (FDG) positron emission tomography (PET)/CT scan demonstrated uptake in the lung parenchyma and spleen indicative of sarcoidosis inflammatory activity. Bronchoalveolar lavage fluid analysis revealed a cellular pattern compatible with sarcoidosis (a lymphocytosis of $26 \%$ ) [8]. A lung biopsy showed granulomas consistent with sarcoidosis with birefringent material. A detailed history excluded occupational or environmental exposure to silica. However, she had eight cats and four of them were sleeping in two cat boxes in her bedroom. Treatment with prednisone was started. As her clinical situation did not improve after 2 months, methotrexate (MTX) (12.5 mg once a week orally with $5 \mathrm{mg}$ folic acid once a week, taken on a different day to the MTX) was added. We also advised her to temporarily avoid any contact with the cats, especially the cat litter.

The patient's clinical condition improved dramatically within 6 months, and we were able to taper off the prednisone and finally stop the MTX after $1 \mathrm{yr}$ of treatment. At that time, ACE $\left(20 \mathrm{U} \cdot \mathrm{L}^{-1}\right)$ and $\mathrm{sIL}-2 \mathrm{R}\left(2,361 \mathrm{pg} \cdot \mathrm{L}^{-1}\right)$ were within normal limits. Moreover, a control PET/CT scan was negative. As she felt much better, she decided to take back her cats and 2 months later, her clinical situation deteriorated and all earlier signs of sarcoidosis activity returned. Since she adored her cats so much, we advised her to search for silica-free cat litter. She found a cat litter made out of old newspapers, without silica and that was not dusty. Shortly after starting to use this, she felt much better. She was stable for almost 2 yrs without any sign of inflammation associated with sarcoidosis. Thereafter, she visited her son for 3 weeks. He has three cats and the "wrong" cat litter. 1 month later, she deteriorated again and blamed herself for not having the foresight to ask him to replace his cat litter with her own (nonsilica) brand.

Sarcoidosis susceptibility depends on both environmental and genetic modifiers $[1,4,5]$. Inflammation in sarcoidosis is characterised by ongoing T-cell and macrophage activity and granuloma formation reflected by an increase of serological markers of inflammation or abnormality in glucose metabolism demonstrated as high uptake on ${ }^{18} \mathrm{~F}-\mathrm{FDG}$ PET/CT $[4,9]$. Moreover, the endogenous antioxidant defence was found to be significantly reduced in sarcoidosis, indicating that oxidative 


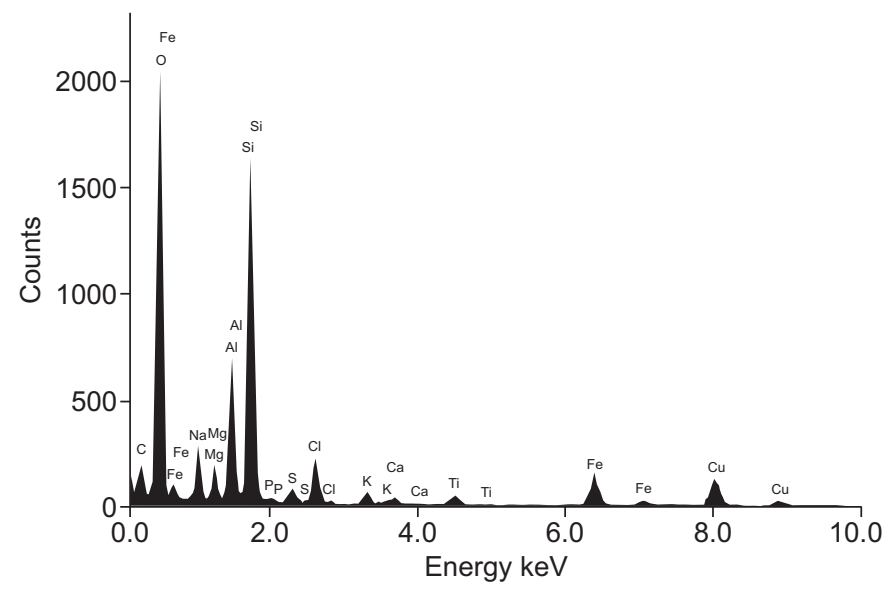

FIGURE 1. Energy-dispersive X-ray spectrum analysis of cat litter used by the presented patient with peaks of silica $(1.740 \mathrm{keV})$ and aluminium $(1.486 \mathrm{keV})$ particularly evident. The peaks for sulfur, chlorine, potassium, titanium, iron and copper originate from the supporting material.

stress underlies the pathology of this disease $[10,11]$. Silica granulomatosis is a delayed hypersensitivity response to crystalline silica. The biological plausibility of a relationship between exposure to silica and autoimmune and inflammatory disorders has already been proposed [1-3]. Recently, SoLÀ et al. [6] reported a very interesting case suggesting a new association between ingestion of anhydrous colloidal silica (a vehicle for some oral drug formulations) and sarcoidosis. In our case, the suggestion is that the response to silica, a component of the cat litter, is probably the end result of an immune and inflammatory response in a genetically susceptible host [6]. Similar reactions related to exposure to talc, a group of hydrous magnesium silicates, have been reported [12].

The clinical condition improved within 6 months after withdrawal of the silica-containing cat litter. However, the patient deteriorated twice after autoprovocation by the return of the cats and litter boxes. This temporary clinical improvement strongly implicates silica as the cause of the patient's sarcoidosis, since the symptoms were induced after exposure to the cat litter containing crystalline silica and disappeared when exposure was terminated. Energy-dispersive X-ray spectrum analysis of small samples of the cat litter showed peaks of mainly silica (fig. 1).

This admittedly exceptional case shows that caution should always be exercised when making a diagnosis of sarcoidosis and that recreational, as well as occupational and environmental exposures, must be considered. Furthermore, it underlines the extreme importance of a thorough exposure history. It would be very challenging to explore whether this observation is only anecdotal or could be an explanation for the development of similar "sarcoid-like" reactions in more cases. Although crystalline silica exposure has been known to be associated with sarcoidosis, the present case provides evidence of an unexpected association between the substantial exposure to silica-containing cat litter and sarcoidosis or a "sarcoid-like" granulomatous reaction. Obviously, this is important, as many people have cats with litter boxes. Therefore, it was recommended not to get rid of the cats but rather choose appropriate cat litter, without silica. This case stresses: "if you are not aware of it, you will not recognise it!"

\section{Drent ${ }^{*, \#}$, P.A. Wijnen ${ }^{\uparrow}$, A.W. Boots ${ }^{+}$and A. Bast ${ }^{*+}$}

*ILD Care Team, Depts of "Respiratory Medicine, "Clinical Chemistry, Maastricht University Medical Centre, and ${ }^{+}$Dept of Toxicology, University Maastricht, Maastricht, The Netherlands.

Correspondence: M. Drent, University of Maastricht, PO Box 3100, 6202 NC Maastricht, The Netherlands. E-mail: ildcare@ gmail.com

\section{Statement of Interest: None declared.}

Acknowledgements: The authors acknowledge P.H.H. Bomans (Technical University Eindhoven, Eindhoven, the Netherlands) for performing the electron microscopy analysis.

\section{REFERENCES}

1 Culver DA, Newman LS, Kavuru MS. Gene-environment interactions in sarcoidosis: challenge and opportunity. Clin Dermatol 2007; 25: 267-275.

2 Drent M, Bomans PH, Van Suylen RJ, et al. Association of manmade mineral fibre exposure and sarcoidlike granulomas. Respir Med 2000; 94: 815-820.

3 Rafnsson V, Ingimarsson O, Hjalmarsson I, et al. Association between exposure to crystalline silica and risk of sarcoidosis. Occup Environ Med 1998; 55: 657-660.

4 Iannuzzi MC, Rybicki BA, Teirstein AS. Sarcoidosis. N Engl J Med 2007; 357: 2153-2165.

5 Nathan C. Points of control in inflammation. Nature 2002; 420: 846-852.

6 Solà R, Boj M, Hernandez-Flix S, et al. Silica in oral drugs as a possible sarcoidosis-inducing antigen. Lancet 2009; 373: 1943-1944.

7 Calvert GM, Rice FL, Boiano JM, et al. Occupational silica exposure and risk of various diseases: an analysis using death certificates from 27 states of the United States. Occup Environ Med 2003; 60: $122-129$.

8 Drent M, Jacobs JA, Cobben NA, et al. Computer program supporting the diagnostic accuracy of cellular BALF analysis: a new release. Respir Med 2001; 95: 781-786.

9 Keijsers RG, Verzijlbergen JF, van Diepen DM, et al. ${ }^{18}$ F-FDG PET in sarcoidosis: an observational study in 12 patients treated with infliximab. Sarcoidosis Vasc Diffuse Lung Dis 2008; 25: 143-149.

10 Koutsokera A, Papaioannou AI, Malli F, et al. Systemic oxidative stress in patients with pulmonary sarcoidosis. Pulm Pharmacol Ther 2009; 22: 603-607.

11 Drent M, van den Berg R, Haenen GR, et al. NF-кB activation in sarcoidosis. Sarcoidosis Vasc Diffuse Lung Dis 2001; 18: 50-56.

12 Iqbal A, Aggarwal B, Menon B, et al. Talc granulomatosis mimicking sarcoidosis. Singapore Med J 2008; 49: e168-e170.

DOI: $10.1183 / 09031936.00074411$ 